\title{
The temperature dimension of the seed germination niche in fen wetlands
}

\author{
Eduardo Fernández-Pascual ${ }^{1 *}$, Borja Jiménez-Alfaro ${ }^{1}$, Tomás Emilio Díaz ${ }^{1}$ \\ 1'Jardín Botánico Atlántico, Universidad de Oviedo, Avda. del Jardín Botánico 2230, 33394 Gijón/Xixón, Spain \\ *Correspondence: Email eduardofp@indurot.uniovi.esTelephone: 0034985185134; Fax: 0034985130685
}

This is a pre-copyedited, author-produced PDF of an article accepted for publication in Plant Ecology. The version of record (Fernández Pascual, E., Jiménez-Alfaro, B. \& Díaz González, T.E. (2013) The temperature dimension of the seed germination niche in fen wetlands. Plant Ecology 214: 489-499) is available online at: http://dx.doi.org/10.1007/s11258-012-0165-7.

\begin{abstract}
The seed germination niche partly determines adaptation, ecological breadth and geographic range in plant species. In temperate wetlands environmental temperature is the chief regulator of germination timing, but the ecological significance of high and low temperatures during dormancy break and germination is still poorly understood. Our aim was to characterize the temperature dimension of the germination niche in mountain base-rich fens, determining (1) the effect of different temperatures on dormancy break and germination, and (2) whether different germination strategies may be identified at the species level. We conducted laboratory germination experiments with seeds of 15 species from these habitats, collected in 18 fen sites in the Cantabrian Mountains (Spain) for two consecutive years. In all the species the seeds were totally or conditionally dormant at dispersal and stratification produced a significant increase of germination. In most cases there was not an obligatory requirement for cold temperatures during dormancy break, since warm stratification promoted germination as well. Although the optimal germination thermoperiod was generally high $\left(30 / 20^{\circ} \mathrm{C}\right)$, most species could also germinate at lower temperatures after cold-stratification. We also identified a group of species associated to cold-water springs that germinated only at low temperatures. Our results demonstrate that dormancy break in mountain base-rich fens does not obligatorily depend on cold temperatures during overwintering. Furthermore, germination at cool temperatures may be more widespread in wetland habitats than previously thought. The existence of two distinctive germination strategies, 'warm' and 'cool', can potentially give rise to divergent species responses to climate change.
\end{abstract}

\section{Keywords:}

Base-rich fens; Calcareous spring fens; Dormancy; Ecophysiology; Regeneration niche; Seed Ecology

\section{Introduction}

The range of conditions under which a seed may germinate is its germination niche, a key aspect of the plant regeneration niche (Grubb 1977) that determines adaptation, ecological breadth and geographic range in plant species (Donohue et al. 2010). Among the various dimensions or factors that make up the germination niche, environmental temperature is of paramount importance, influencing both seed dormancy and germination (Fenner and Thompson 2005). In general terms, seeds of a given species may germinate over a particular range of temperatures, with upper and lower thresholds beyond which no germination occurs. In many species, however, this seed germination range is in turn regulated by the environment through physiological dormancy (Baskin and Baskin 2004), a seed characteristic that modifies the germination temperature thresholds (Baskin and Baskin 1998) and defines the environmental conditions that must be met before germination can occur (Finch-Savage and Leubner-Metzger 2006). By means of these processes, environmental temperature controls germination timing and the environment experienced by subsequent life stages (Donohue
2005). Germination timing is especially important in seasonal climates, where it is subjected to natural selection and also determines the action of natural selection in other life history traits (Donohue et al. 2005a,b,c). Understanding the relationships between the germination niche and the environment is therefore crucial for assessing the adaptation of plants to their habitats, as well as the effect of the projected rise of world temperatures which could potentially disrupt such relationships (Cochrane et al. 2010; Mondoni et al. 2012).

In wetland habitats, the germination niche of emergent species (i.e., those rooted in water at least temporarily, but with stems and leaves permanently above the water table) is generally characterized by physiological dormancy and optimal germination at high temperatures $\left(>25^{\circ} \mathrm{C}\right)$ while being prevented by low ones $\left(<15^{\circ} \mathrm{C}\right)$ (reviewed in Baskin and Baskin 1998). This 'warm germination' pattern was first described in the comparative studies of Grime et al. (1981) and Thompson and Grime (1983), who noted a widespread requirement for fluctuating or unusually high temperatures in wetland species and explained it as a mechanism which detects the fall of the water table in spring, marking the beginning of 
the growing season. More recently, research has focused in wetland Carex L. species from Central Europe (Schütz 1997, 2000; Schütz and Rave 1999, 2003) and North America (Budelsky and Galatowitsch 1999; Kettenring et al. 2006; Kettenring and Galatowitsch 2007a,b) confirming that they follow and exemplify the 'traditional' wetland germination pattern: conditional physiological dormancy at dispersal, a requirement for light and fluctuating temperatures, and a preference for high or unusually high $\left(\right.$ c. $\left.30^{\circ} \mathrm{C}\right)$ germination temperatures. According to Baskin and Baskin (1998), these characteristics would allow the seeds to lose their dormancy during the flooded winter season and germinate as soon as the water recedes. Such interpretation is mainly based on species living on habitats with seasonal hydrological regimes where the water table changes periodically (such as temporary ponds and lake margins) but there are less studies focused on other wetlands. It is still necessary to conduct multispecies research over the main plant communities that may be recognized in different wetland habitats.

Here, we study the germination niche in baserich fens, a particular type of wetlands which occur in the temperate regions of the world (Hájek et al. 2006). The water level in these fens depends only indirectly on precipitation and the soils remain water saturated throughout the year. Despite their high conservation concern (van Diggelen et al. 2006; Bergamini et al. 2009), the germination patterns of base-rich fen plant communities have been seldom studied, especially in mountainous regions where they are expected to be highly sensitive to global warming (Essl et al. 2012). To our knowledge, community-level assessments of germination have been exclusively conducted in lowland fen grasslands, semi-natural meadows created from natural fens as a consequence of traditional agriculture (Maas 1989; Patzelt et al. 2001; Jensen 2004). Almost all the species tested in these studies had physiological dormancy, with a germination promoting effect of cold stratification. There is a caveat, however, to the interpretation of cold effects in dormancy loss: since only fresh versus coldstratified seeds were tested, it is not possible to determine whether the dormancy loss required cold temperatures, or was produced simply by the longer wet incubation in comparison with the fresh seeds. In light of the importance it may have in determining the effect of climate change on plant regeneration (Walck et al. 2011; Ooi 2012), the role of cold in dormancy loss should be more clearly assessed. Regarding germination temperature, Maas (1989), and Patzelt et al. (2001) compared constant versus alternating thermoperiods and found an inhibitory effect of constant temperatures in germination. However, only cool to moderate thermoperiods $\left(15 / 5{ }^{\circ} \mathrm{C}, 22 / 12^{\circ} \mathrm{C}, 25 / 10{ }^{\circ} \mathrm{C}\right.$ and $\left.25 / 15{ }^{\circ} \mathrm{C}\right)$ were tested, and therefore they did not address the effect of unusually high and alternating temperatures, which have been found to be optimal in most wetland species. Some species such as Primula farinosa L. (Patzelt et al. 2001) and Triglochin palustris L. (Jensen 2004) germinated well under relatively cool thermoperiods $\left(15 / 5^{\circ} \mathrm{C}\right)$ but it remains to be seen if they can also germinate under the 'warm germination' pattern recognized in wetland habitats (and thus share a broader but overlapping germination niche) or they do not (and follow an alternative germination strategy). Comparing the germination response to a broad temperature range in different base-rich fen species is necessary to fully characterize the germination niche in these habitats.

The main aim of this work was to investigate the temperature dimension of the germination niche in mountain base-rich fens. We performed laboratory experiments with seeds of 15 species from these habitats to address the following specific questions: (1) How widespread is seed dormancy at dispersal and what role does cold temperature play during dormancy break? (2) What is the germination response to spring/autumn, summer and unusually warm thermoperiods? (3) Is the germination niche in base-rich fens characterized by a common pattern, or may different germination strategies be identified at species level?

\section{Material and methods}

\section{Study system}

The study took place in the Cantabrian Mountains of north-western Spain $\left(43^{\circ} 12^{\prime}\right.$ N 5 $\left.5^{\circ} 7^{\prime} \mathrm{W}\right)$, where base-rich fens are relatively widespread and support most of the European specialist species of these habitats (Jiménez-Alfaro et al. 2012). We selected 18 sites (Fig. 1) among those commonly referred in the literature as well-developed base-rich fen communities, encompassing their whole altitudinal gradient in the study area ( 710 to $1870 \mathrm{~m}$ above sea level) and distributed along $140 \mathrm{~km}$ from west to east. To record soil temperature during the year, in June 2010 we placed three dataloggers (M-Log5W, GeoPrecision GmbH, Ettlingen, Germany) in three sites covering the entire altitude gradient, burying them $5 \mathrm{~cm}$ in the soil in a flat and central area. In the period from September 2010 to August 2011, day/night soil temperature $\left({ }^{\circ} \mathrm{C}\right)$ ranged from $16 / 13$ at the lowest site to $8 / 6$ at the highest in autumn, $9 / 7$ to $4 / 3$ in winter, $13 / 11$ to $9 / 6$ in spring and $19 / 16$ to $13 / 10$ in summer.

The experiments included 15 species mainly restricted to base-rich fens and related habitats (mires with $\mathrm{pH}>6.5$ ) in the study area (Table 1), including some of the plant specialists recognized in similar communities of other European mountains (Bergamini et al. 2006). We collected seeds of the study species during the dispersal seasons (June to September) of 2010 and 2011. To take account of possible within-species variation, we carried out 
repeated collections of the same species in different sites and years (Table 1), although in some cases one or both factors could not be replicated as a result of inadequate seed availability. Seed sampling regularly covered the entire area of occupancy of the species at a given site and included all the individuals bearing ripe seeds (i.e., fully matured fruits that could be easily detached from the mother plant). After collection the fruits spent three weeks in our laboratory (c. $22^{\circ} \mathrm{C}, 50 \% \mathrm{RH}$ ) to ensure homogeneous maturation; subsequently we cleaned the seeds and began the germination experiments.

\section{Germination experiments}

We conducted laboratory germination experiments on $1 \%$ distilled water agar, held in Petri dishes sealed with parafilm to prevent desiccation (four dishes with 25 seeds each per experimental treatment). The experiments had a fully factorial design with two factors: pre-treatment and germination thermoperiod. To assess seed dormancy, the dishes were subjected to one of the following pretreatments: (1) fresh; where seeds were incubated at the germination thermoperiods immediately after sowing; and (2) cold-stratification; where after sowing the seeds were kept at $3^{\circ} \mathrm{C}$ in darkness for 12 weeks prior to incubation at the germination thermoperiods. Additionally, in order to ascertain the role of cold during dormancy break, the seeds of the fresh pre-treatment that did not germinate during their first incubation at the germination thermoperiods were subjected to (3) warm stratification at $25^{\circ} \mathrm{C}$ in darkness for eight weeks; and then incubated for a second time at the same germination thermoperiods (the results for this pretreatment included germination during the first incubation). To determine the germination response to temperature, we incubated the dishes for four weeks under three germination thermoperiods: $14 / 4^{\circ} \mathrm{C}$ (spring/autumn), $22 / 12^{\circ} \mathrm{C}$ (summer) and $30 / 20^{\circ} \mathrm{C}$ (unusual heat). The thermoperiods were programmed in growth chambers (Grow-S 360, Ing. Climas, Barcelona, Spain) and coupled with a $12 \mathrm{~h}-$ light/12h-darkness photoperiod (c. $20 \mu \mathrm{mol} . \mathrm{m}^{-2} \cdot \mathrm{s}^{-1}$ during the light phase, provided by six Philips TLD30W/54-765 cool fluorescent tubes). During the incubations we counted and discarded germinated seeds weekly (radicle emergence was the criterion for germination) and after the experiments we opened the non-germinated seeds with a scalpel, classifying them as normal, empty and fungus infected. We excluded the empty and infected seeds from the calculation of germination percentages and the statistical analyses. Some treatments that lacked variance (i.e., germination $=0$ or $100 \%$ ) had to be transformed (to germination $=1$ or $99 \%$ ) so they could be included in the statistical tests.

\section{Data analysis}

We analysed the effect of the experimental treatments on germination (separately for each species) by fitting Generalized Linear Mixed Models (GLMM, binomial error distribution, logit link function) with the experimental treatments as fixed factors and seed collection as a random factor. First, we fitted main effects GLMM with the three levels of thermoperiod and two levels of pre-treatment to establish if there were significant differences in seed germination between (1) fresh and cold-stratified seeds; (2) fresh and warm-stratified seeds; (3) coldand warm-stratified seeds. Afterwards, we performed pairwise GLMM comparisons within pretreatments to determine (4) which germination thermoperiods produced significantly different results in the fresh and (5) in the cold-stratified seeds. We fitted the GLMMs using SPSS (version 20.0, IBM, Armonk, New York, USA). Finally, to assess germination niche variability among the study species, we carried out a Principal Component Analysis (PCA) using germination per collection as multivariate variables (mean germination values for fresh and cold-stratified seeds in the three germination thermoperiods). We computed the PCA using the correlation coefficient as implemented in the PAST software (Hammer et al. 2001), and used the two main PCA axes to identify similar germination responses in the ordination space.

\section{Results}

\section{Pre-treatments}

The range of tested conditions was generally successful in promoting germination, as in 14 out of 15 species more than $85 \%$ of the seeds germinated in at least one collection and treatment, the exception being $C$. somedanum. In $C$. somedanum, $P$. mixta and $P$. grandiflora the germination of the fresh seeds was zero or almost zero, while in the rest of the species significant fresh germination occurred in at least one of the germination thermoperiods (Fig. 2). The GLMM (Table 2) confirmed that, taking into account the variation among seed collections, cold stratification had a significant effect on seed germination in all the species, producing a significant increase from fresh seed germination in at least one of the germination thermoperiods (Fig. 2). Similarly, warm stratification produced a significant increase from fresh germination in most species, except for $B$. compressus, $P$. mixta and $P$. farinosa where it had no effect (Fig. 2). Even so, in most of the species where both stratifications had a significant effect, this effect was not the same (Fig. 2). In C. davalliana, C. diandra, C. echinata, $C$. lepidocarpa, $P$. palustris, $P$. grandiflora and $S$. perennis cold stratification produced significantly better results, with higher germination percentages and germination at more thermoperiods. Conversely, warm stratification produced significantly better results in C. pulicaris and J. alpino-articulatus. The effect of the two stratification types was not 
significantly different in $C$. somedanum and $T$. palustris. In E. latifolium the two stratifications were as well not significantly different, but in this case it was due to exceptionally high dark germination during warm stratification of the seeds from the $14 / 4^{\circ} \mathrm{C}$ thermoperiod, probably produced by the transfer to warmer temperatures $\left(25^{\circ} \mathrm{C}\right)$. Excluding this artefact, cold stratification produced significantly $(\mathrm{F}=311.556, \mathrm{p}<0.001)$ better results in E. latifolium.

\section{Germination thermoperiods}

The germination thermoperiod that produced significantly (Table 3 ) better results was $30 / 20^{\circ} \mathrm{C}$ in most species (Fig. 2); although in C. echinata optimal germination extended also to $22 / 12^{\circ} \mathrm{C}$. In $C$. pulicaris and $J$. alpino-articulatus the best results occurred at $22 / 12^{\circ} \mathrm{C}$; and only in P. mixta was $14 / 4^{\circ} \mathrm{C}$ the optimal germination thermoperiod. $P$. grandiflora and $C$. somedanum germinated equally well at $22 / 12^{\circ} \mathrm{C}$ and $14 / 4^{\circ} \mathrm{C}$, although in the latter species germination was relatively low $(51 \pm 7 \%)$ indicating that either dormancy was not fully broken or that the optimal germination temperature was even lower.

\section{Species ordination}

The first two PCA axes (Fig. 3) accounted for $72 \%$ of the total variance. The first axis (51\% of explained variation) showed a high positive correlation ( $\mathrm{r}>$ $0.6)$ with all the germination variables, and clearly separated the collections of three species (Group A) characterized by high germination $(>85 \%)$ at the three thermoperiods after cold stratification (Table $4)$. On the other hand, differences along the second axis (21\% of explained variation) were mainly correlated with the germination of stratified seeds at $14 / 4^{\circ} \mathrm{C}(\mathrm{r}=0.6)$ and $30 / 20^{\circ} \mathrm{C}(\mathrm{r}=-0.65)$. Such differences separate a main group of species having similar germination responses to high temperatures (Group B) from another five species (Group C) in which optimal germination occurred at cool or moderate temperatures (Table 4). In general, the collections from a same species showed a congruent distribution along the ordination axes, although two species ( $S$. perennis and C. lepidocarpa) showed a relative higher variation.

\section{Discussion}

The germination niche in most of the species analyzed in this study is characterized by dormancy at dispersal and optimal germination at unusually high temperatures, as is generally the case in wetland species (Grime et al. 1981; Thompson and Grime 1983; Baskin and Baskin 1998; Schütz 2000). Nonetheless, two caveats must be made. First, contrary to what is frequently assumed (Schütz and Rave 1999; Kettenring and Galatowitsch 2007) the requirement for cold temperatures during dormancybreaking stratification is not obligatory but facultative in most of the cases (i.e. although cold improves germination percentages and broadens the germination temperature range, dormancy break occurs as well at warm temperatures, albeit at a slower rate). Second, unlike in a majority of wetland species (Baskin and Baskin 1998), germination in mountain base-rich fens may also occur at relatively cool temperatures, which are more realistic in the permanently water-saturated soils of these habitats.

\section{Seed dormancy}

Since stratification improved seed germination in all our species, we can conclude that all of them have dormancy at dispersal, as has been found in most fen grassland species (Maas 1989; Patzelt et al. 2001; Jensen 2004). Still, the degree and characteristics of dormancy vary greatly among them. In $C$. somedanum, $P$. mixta and $P$. grandiflora dormancy at dispersal is total as fresh germination is marginal across the entire germination temperature range. More frequently, the species show conditional dormancy (i.e., some fresh germination occurs in part of the germination temperature range; Baskin and Baskin 1998).

In all species, dormancy break produces both an increase in germination percentages and a broadening of the temperature range where significant germination takes place. In $B$. compressus, $P$. farinosa and $P$. mixta dormancy break occurs exclusively during cold stratification, and thus they have an obligatory requirement for cold per se. In most of the study species, however, the cold requirement is facultative because they also lose dormancy during warm stratification but the effect of cold is more intense. Our study shows that in these cases the main role of cold temperatures during dormancy break is to allow germination at autumn/spring temperatures, which would not produce germination had the temperature during stratification been warm. On the other hand, some species respond equally to warm and cold ( $T$. palustris, $C$. somedanum) or even better to warm ( $C$. pulicaris, J. alpino-articulatus) stratification and consequently they have not a requirement for cold perse.

Judging by the positive effect of stratification, the most probable type of seed dormancy in all of our species is physiological (sensu Baskin and Baskin 2004). Nonetheless, as no embryo measurements were made, we cannot exclude a morphological component of dormancy (Baskin and Baskin 2005). For example, Fernández-Pascual et al. (2012) found morphophysiological dormancy in $C$. somedanum, and it may be that more of our species share this kind of germination delay, especially the ones where warm stratification has the same or a better effect than cold.

\section{Warm germination}


In the majority of the study species, optimal germination occurs at unusually high temperatures $\left(30 / 20^{\circ} \mathrm{C}\right)$. This 'warm germination' is characteristic of wetland species (Grime et al. 1981; Thompson and Grime 1983) and especially of the genus Carex (Schütz 2000). However, according to the data collected by our dataloggers, such thermoperiod may be rather unusual in the soil of mountain base-rich fens. At least in the 2010-2011 season, soil temperature never attained so high values: $25^{\circ} \mathrm{C}$ were only exceeded for two days in the medium altitude site, while the temperature was always less than $22^{\circ} \mathrm{C}$ in the lowest and $18^{\circ} \mathrm{C}$ in the highest sites. Although temperature in the immediate surface can be potentially warmer in bright sunlight, the top layers of the fen are made up by bryophytes and the water flows drain the seeds into the deeper layers, which are permanently saturated by cold mountain spring waters which stabilize soil temperatures and keep them cool.

That being the case, values around $30^{\circ} \mathrm{C}$ will only be reached in extraordinary situations when parts of the fen become dried. In such a scenario, mortality of existing vegetation may follow, and thus gaps may appear for new individuals. As the $30 / 20^{\circ} \mathrm{C}$ temperature regime not only produces optimal germination in non dormant seeds (i.e., after stratification), but also triggers fresh seed germination in most of our species, it may serve as a gap detecting mechanism which quickly overrides seed dormancy and produces 'short term' germinative responses in certain extraordinary situations where high recruitment becomes favourable.

Even so, in regular conditions, soil temperatures will be more similar to our $22 / 12^{\circ} \mathrm{C}$ and especially $14 / 4^{\circ} \mathrm{C}$ thermoperiods. In this scenario, when no gaps occur as a consequence of episodes of soil drying, seeds will follow a 'long term' germinative path: after dispersal in autumn germination will be prevented by dormancy; the cold winter season will produce dormancy break; and seeds will germinate as temperatures become warmer in spring and summer. Patzelt et al. (2001) and Jensen (2004) already found germination at $15 / 5^{\circ} \mathrm{C}$ in some fen species, and it seems that the capacity to germinate at such thermoperiods is relatively widespread in mountain base rich fen species once dormancy is broken.

\section{Specific germination strategies}

The short term 'warm germination' response, however, is not uniformly shared by all mountain base-rich species. The species we included under groups A and B follow the traditional wetland 'warm germination' strategy. Although in both groups fresh germination occurs at $30 / 20^{\circ} \mathrm{C}$ and cold stratification produces a broadening of the germination niche towards cooler temperatures, in group $\mathrm{A}$ this broadening is significantly greater and so is the capacity to germinate at $14 / 4^{\circ} \mathrm{C}$. As a consequence, the majority of seedling emergence in group $\mathrm{A}$ species is expected to take place shortly after dispersal or the next spring, while most group B species would wait until the summer or even delay germination until the next year. Such differences may be related to the broader habitat specialization in group A species, since $T$. palustris can be found in both coastal and mountain marsh areas and $C$. echinata has a wider ecological range along the $\mathrm{pH}$ gradient of mountain fens (Hájek et al. 2006). $P$. farinosa, on the other hand, is a plant specialist closely related to base-rich fens but has been characterized as having a restricted ability to colonize new sites (Hájek et al. 2011). The broad germination niche we found in this species suggests that this restriction is not related to the germination stage of the regeneration cycle.

Species assigned to Group C clearly depart from the traditional wetland 'warm germination' pattern as their germination is reduced or even prevented by unusually high temperatures. These species also show differences in seed dormancy, as it includes species that either have total instead of conditional dormancy at dispersal, or which respond better to warm stratification. In the Iberian Peninsula, $C$. somedanum, J. alpino-articulatus and $P$. grandiflora are usually associated to mountain spring fens, which differ from flat fens in that they are more intensely influenced by the spring water and have steeper slopes (Jiménez-Alfaro et al. 2011). In these particular fen habitats episodes of soil drying and heating are not expected; quite on the contrary, their temperature is kept stable and cool by the spring waters. In a previous work, we already defined $C$. somedanum as following a 'mountain spring' germination strategy (Fernández-Pascual et al. 2012), and it would seem that this type of germination behaviour is not uncommon in mountain spring fens.

\section{Conclusions}

The temperature dimension of the germination niche in mountain base-rich fens may embody two general strategies. The traditional wetland 'warm germination' strategy is characterized by a dual germinative path. 'Short-term' responses to high temperature override dormancy and may allow the species to detect gaps produced by episodes of soil drying. In the absence of such drying events, the 'long-term' path follows through conditional dormancy at dispersal, dormancy break during overwintering and spring/summer germination at lower temperatures. An alternative germination strategy is followed by a group of 'cool germination' species, mostly related to spring fen habitats. These species lack the 'short-term' response to soil heat and may germinate only at low temperatures. 
In any case, the strategies here described are based on laboratory germination experiments and in situ measured temperature, and therefore their direct application to field conditions must be interpreted with care. It will be necessary to conduct field experiments to corroborate if the predicted emergence patterns are observed in nature. Additionally, it would be interesting to assess the potential effects of global warming on these germination strategies. Climate change is expected to alter the rate of dormancy loss and germination (Walck et al. 2011). In the case of base-rich fens, warming could differentially affect the regeneration of 'warm' and 'cool' germinators, producing an alteration of the vegetation composition and a subsequent detrimental effect on fen survival and conservation.

\section{Acknowledgements}

E. Aguado Basabe, R. Carro Machín, E. Correia Álvarez, C. García de Pedro, A.I. García Torrico, M. Hájek and P. Hájková contributed to seed collection; which was authorized by the regional governments of Asturias, Cantabria and Castile-Leon. The authors thank two anonymous reviewers for their comments on the manuscript. E.F.P. received a grant from the Government of Asturias (Programa "Severo Ochoa" de Ayudas Predoctorales; Plan de Ciencia, Tecnología e Innovación del Principado de Asturias); B.J.A. from the European Social Fund through the Spanish Ministry of Science (PTA20070726-I).

\section{References}

Baskin CC, Baskin JM (1998) Seeds. Ecology, Biogeography, and Evolution of Dormancy and Germination. Academic Press, San Diego, USA

Baskin CC, Baskin JM (2005) Underdeveloped embryos in dwarf seeds and implications for assignment to dormancy class. Seed Sci Res 15:357-360

Baskin JM, Baskin CC (2004) A classification system for seed dormancy. Seed Sci Res 14:1-16

Bergamini A, Peintinger M, Fakheran S, Moradi H, Schmid B, Joshi J (2009) Loss of habitat specialists despite conservation management in fen remnants 1995-2006. Perspect Plant Ecol Evol Syst 11:65-79

Budelsky RA, Galatowitsch SM (1999) Effects of moisture, temperature, and time on seed germination of five wetland Carices: Implications for restoration. Restor Ecol 7:86-97

Cochrane A, Daws MI, Hay F (2011) Seed-based approach for identifying flora at risk from climate warming. Austral Ecol 36:923-935

Donohue K (2005) Niche construction through phenological plasticity: Life history dynamics and ecological consequences. New Phytol 166:83-92

Donohue K, de Casas RR, Burghardt L, Kovach K, Willis CG (2010) Germination, postgermination adaptation, and species ecological ranges. Annu Rev Ecol Evol Syst 41:293-319

Donohue K, Dorn L, Griffith C, Kim E, Aguilera A, Polisetty CR, Schmitt J (2005a) Environmental and genetic influences on the germination of Arabidopsis thaliana in the field. Evolution 59:740-757

Donohue K, Dorn L, Griffith C, Kim E, Aguilera A, Polisetty CR, Schmitt J (2005b) The evolutionary ecology of seed germination of Arabidopsis thaliana: Variable natural selection on germination timing. Evolution 59:758-770

Donohue K, Dorn L, Griffith C, Kim E, Aguilera A, Polisetty CR, Schmitt J (2005c) Niche construction through germination cueing: Life-history responses to timing of germination in Arabidopsis thaliana. Evolution 59:771-785

Essl F, Dullinger S, Moser D, Rabitsch W, Kleinbauer I (2012) Vulnerability of mires under climate change: Implications for nature conservation and climate change adaptation. Biodivers Conserv 21:655-669

Fenner M, Thompson K (2005) The Ecology of Seeds. Cambridge University Press, Cambridge, UK

Fernández-Pascual E, Jiménez-Alfaro B, García-Torrico AI, Pérez-García F, Díaz TE (2012) Germination ecology of the perennial Centaurium somedanum, a specialist species of mountain springs. Seed Sci Res 22:199-205

Finch-Savage WE, Leubner-Metzger G (2006) Seed dormancy and the control of germination. New Phytol 171:501-523

Grime JP, Mason G, Curtis AV, Rodman J, Band SR, Mowforth MAG, Neal AM, Shaw S (1981) A comparative study of germination characteristics in a local flora. J Ecol 69:1017-1059

Grubb PJ (1977) The maintenance of species-richness in plant communities: The importance of the regeneration niche. Biol Rev 52:107-145

Hájek M, Horsák M, Hájková P, Díte D (2006) Habitat diversity of Central European fens in relation to environmental gradients and an effort to standardise fen terminology in ecological studies. Perspect Plant Ecol Evol Syst 8:97-114

Hájek M, Horsák M, Tichý L, Hájková P, Díte D, Jamrichová E (2011) Testing a relict distributional pattern of fen plant and terrestrial snail species at the Holocene scale: a null model approach. J Biogeogr 38:742-755

Hammer $\varnothing$, Harper DAT, Ryan PD (2001) PAST: Paleontological statistics software package for education and data analysis. Palaeontologia Electronica 4:1-9

Jensen K (2004) Dormancy patterns, germination ecology, and seed-bank types of twenty temperate fen grassland species. Wetlands 24:152-166

Jiménez-Alfaro B, Díaz González T, Fernández-Pascual E (2011) Grupos de vegetación y hábitats de tremedales neutro-basófilos en las montañas pirenaico-cantábricas. Acta Botanica Barcinonensia 53:47-60

Jiménez-Alfaron B, Fernández-Pascual E, Díaz González T, Pérez-Haase A, Ninot J (2012) Diversity of rich fen vegetation and related plant specialists in mountain refugia of the Iberian Peninsula. Folia Geob. doi: 10.1007/s12224-012-9125-1

Kettenring KM, Galatowitsch SM (2007a) Temperature requirements for dormancy break and seed germination vary greatly among 14 wetland Carex species. Aquat Bot 87:209220

Kettenring KM, Galatowitsch SM (2007b) Tools for Carex revegetation in freshwater wetlands: Understanding dormancy loss and germination temperature requirements. Plant Ecol 193:157-169

Kettenring KM, Gardner G, Galatowitsch SM (2006) Effect of light on seed germination of eight wetland Carex species. Ann Bot 96:869-874

Maas D (1989) Germination characteristics of some plant species from calcareous fens in southern Germany and their implications for the seed bank. Holarctic Ecol 12:337-344

Mondoni A, Rossi G, Orsenigo S, Probert RJ (2012) Climate warming could shift the timing of seed germination in alpine plants. Ann Bot 110:155-164

Ooi MKJ (2012) Seed bank persistence and climate change. Seed Sci Res 22:53-60.

Patzelt A, Wild U, Pfadenhauer J (2001) Restoration of wet fen meadows by topsoil removal: Vegetation development and germination biology of fen species. Restor Ecol 9:127-136

Schütz W (1997) Primary dormancy and annual dormancy cycles in seeds of six temperate wetland sedges. Aquat Bot 59:75-85

Schütz W (2000) Ecology of seed dormancy and germination in sedges (Carex). Perspect Plant Ecol Evol Syst 3:67-89

Schütz W, Rave G (1999) The effect of cold stratification and light on the seed germination of temperate sedges (Carex) from various habitats and implications for regenerative strategies. Plant Ecol 144:215-230

Schütz W, Rave G (2003) Variation in seed dormancy of the wetland sedge, Carex elongata, between populations and individuals in two consecutive years. Seed Sci Res 13:315-322 
Thompson K, Grime JP (1983) A comparative study of germination responses to diurnally-fluctuating temperatures. J Appl Ecol 20:141-146

Van Diggelen R, Middleton B, Bakker J, Grootjans A, Wassen M (2006) Fens and floodplains of the temperate zone: Present status, threats, conservation and restoration. Appl Veg Sci 9:157-162

Table 1 Species included in this study. $\mathrm{N}$ is the number of repeated collections per species (considering both years and sites). The range of fen water $\mathrm{pH}$ (10 measures per site, MM 40 Portable Multimeter, Crison Instruments S.A., Alella, Spain) and altitude in which each species was collected is also indicated

\begin{tabular}{lllrr}
\hline Species & Family & $\mathrm{N}$ & $\mathrm{pH}$ & Altitude (m) \\
\hline Blysmus compressus (L.) Panz. ex Link & Cyperaceae & 6 & $6.6-8.2$ & $710-1870$ \\
Carex davalliana Sm. & Cyperaceae & 4 & $7.3-8.0$ & $1530-1860$ \\
Carex diandra Schrank & Cyperaceae & 3 & $7.0-7.2$ & $1110-1780$ \\
Carex echinata Murray & Cyperaceae & 4 & $6.6-7.6$ & $1440-1860$ \\
Carex lepidocarpa Tausch & Cyperaceae & 8 & $7.3-8.2$ & $710-1870$ \\
Carex pulicaris L. & Cyperaceae & 2 & $6.7-8.0$ & 1420 \\
Centaurium somedanum M. Laínz & Gentianaceae & 1 & $8.0-8.4$ & 1280 \\
Eriophorum latifolium Hoppe & Cyperaceae & 6 & $6.6-8.4$ & $1460-1600$ \\
Juncus alpino-articulatus Chaix & Juncaceae & 2 & $7.3-8.0$ & $1530-1860$ \\
Parnassia palustris L. & Saxifragaceae & 2 & $7.4-7.5$ & $1540-1610$ \\
Pedicularis mixta Gren. & Scrophulariaceae & 2 & $8.0-8.5$ & $1530-1670$ \\
Pinguicula grandiflora Lam. & Lentibulariaceae & 2 & $8.2-8.6$ & 710 \\
Primula farinosa L. & Primulaceae & 2 & $8.5-8.6$ & $710-1200$ \\
Swertia perennis L. & Gentianaceae & 5 & $7.3-7.7$ & $1610-1860$ \\
Triglochin palustris L. & Juncaginaceae & 2 & $7.4-8.1$ & 1420 \\
\hline
\end{tabular}

Walck JL, Hidayati SN, Dixon KW, Thompson KEN, Poschlod P (2011) Climate change and plant regeneration from seed. Glob Change Biol 17:2145-2161 
Table 2 Results of the GLMM comparing the effect of different pre-treatments in seed germination across three germination thermoperiods. The models included seed collection as a random blocking factor

\begin{tabular}{|c|c|c|c|c|c|c|c|c|c|c|c|c|}
\hline \multirow{3}{*}{ Species } & \multicolumn{4}{|c|}{ Fresh vs. Cold-stratified } & \multicolumn{4}{|c|}{ Fresh vs. Warm-stratified } & \multicolumn{4}{|c|}{ Cold vs. Warm-stratified } \\
\hline & \multicolumn{2}{|c|}{ Pre-treatment } & \multicolumn{2}{|c|}{ Thermoperiod } & \multicolumn{2}{|c|}{ Pre-treatment } & \multicolumn{2}{|c|}{ Thermoperiod } & \multicolumn{2}{|c|}{ Pre-treatment } & \multicolumn{2}{|c|}{ Thermoperiod } \\
\hline & $\mathrm{F}$ & $\mathrm{p}$ & $\mathrm{F}$ & $\mathrm{p}$ & $\mathrm{F}$ & $\mathrm{p}$ & $\mathrm{F}$ & $\mathrm{p}$ & $\mathrm{F}$ & $\mathrm{p}$ & $\mathrm{F}$ & $\mathrm{p}$ \\
\hline B. compressus & 154.768 & $<0.001$ & 222.689 & $<0.001$ & 0.057 & 0.812 & 188.706 & $<0.001$ & 151.072 & $<0.001$ & 224.805 & $<0.001$ \\
\hline C. davalliana & 352.815 & $<0.001$ & 172.515 & $<0.001$ & 122.992 & $<0.001$ & 198.045 & $<0.001$ & 183.457 & $<0.001$ & 248.675 & $<0.001$ \\
\hline C. diandra & 94.426 & $<0.001$ & 176.461 & $<0.001$ & 73.619 & $<0.001$ & 176.856 & $<0.001$ & 9.982 & 0.002 & 206.924 & $<0.001$ \\
\hline C. echinata & 405.464 & $<0.001$ & 121.858 & $<0.001$ & 151.770 & $<0.001$ & 193.166 & $<0.001$ & 218.048 & $<0.001$ & 217.333 & $<0.001$ \\
\hline C. lepidocarpa & 269.857 & $<0.001$ & 198.257 & $<0.001$ & 17.693 & $<0.001$ & 162.557 & $<0.001$ & 185.633 & $<0.001$ & 233.003 & $<0.001$ \\
\hline C. pulicaris & 103.020 & $<0.001$ & 77.717 & $<0.001$ & 343.027 & $<0.001$ & 114.533 & $<0.001$ & 178.468 & $<0.001$ & 139.628 & $<0.001$ \\
\hline C. somedanum & 48.585 & $<0.001$ & 10.661 & 0.001 & 39.348 & $<0.001$ & 22.221 & $<0.001$ & 1.098 & 0.307 & 38.637 & $<0.001$ \\
\hline E. latifolium & 309.088 & $<0.001$ & 355.041 & $<0.001$ & 246.668 & $<0.001$ & 211.575 & $<0.001$ & 0.320 & 0.573 & 152.195 & $<0.001$ \\
\hline J. alpino-articulatus & 188.855 & $<0.001$ & 20.426 & $<0.001$ & 276.913 & $<0.001$ & 18.153 & $<0.001$ & 37.860 & $<0.001$ & 49.964 & $<0.001$ \\
\hline P. palustris & 316.655 & $<0.001$ & 44.433 & $<0.001$ & 49.131 & $<0.001$ & 83.928 & $<0.001$ & 207.100 & $<0.001$ & 37.737 & $<0.001$ \\
\hline P. mixta & 166.979 & $<0.001$ & 20.884 & $<0.001$ & 0.185 & 0.669 & 0.842 & 0.437 & 183.608 & $<0.001$ & 19.588 & $<0.001$ \\
\hline P. grandiflora & 321.661 & $<0.001$ & 66.298 & $<0.001$ & 8.332 & 0.006 & 6.479 & 0.003 & 319.418 & $<0.001$ & 51.227 & $<0.001$ \\
\hline$P$. farinosa & 275.400 & $<0.001$ & 56.297 & $<0.001$ & 2.396 & 0.129 & 91.382 & $<0.001$ & 248.881 & $<0.001$ & 52.077 & $<0.001$ \\
\hline S. perennis & 547.588 & $<0.001$ & 185.893 & $<0.001$ & 88.584 & $<0.001$ & 162.258 & $<0.001$ & 361.119 & $<0.001$ & 235.179 & $<0.001$ \\
\hline T. palustris & 59.741 & $<0.001$ & 17.060 & $<0.001$ & 58.085 & $<0.001$ & 15.753 & $<0.001$ & 0.243 & 0.624 & 0.318 & 0.729 \\
\hline
\end{tabular}


Table 3 Results of the GLMM pairwise comparisons analysing significant differences in germination between germination thermoperiods within fresh and cold-stratified seeds. The models included seed collection as a random blocking factor

\begin{tabular}{|c|c|c|c|c|c|c|c|c|c|c|c|c|}
\hline \multirow{3}{*}{ Species } & \multicolumn{6}{|c|}{ Fresh seeds } & \multicolumn{6}{|c|}{ Cold-stratified seeds } \\
\hline & \multicolumn{2}{|c|}{$30 / 20$ vs. $22 / 12$} & \multicolumn{2}{|c|}{$30 / 20$ vs. $14 / 4$} & \multicolumn{2}{|c|}{$22 / 12$ vs. $14 / 4$} & \multicolumn{2}{|c|}{$30 / 20$ vs. $22 / 12$} & \multicolumn{2}{|c|}{$30 / 20$ vs. $14 / 4$} & \multicolumn{2}{|c|}{$22 / 12$ vs. $14 / 4$} \\
\hline & $\mathrm{F}$ & $p$ & $\mathrm{~F}$ & $p$ & $\mathrm{~F}$ & $p$ & $\mathrm{~F}$ & $p$ & $\mathrm{~F}$ & $p$ & $\mathrm{~F}$ & $\mathrm{p}$ \\
\hline B. compressus & 124.186 & $<0.001$ & 101.105 & $<0.001$ & 0.661 & 0.421 & 145.930 & $<0.001$ & 173.406 & $<0.001$ & 67.749 & $<0.001$ \\
\hline C. davalliana & 62.045 & $<0.001$ & 60.730 & $<0.001$ & 0.001 & 0.977 & 5.647 & 0.024 & 214.267 & $<0.001$ & 174.516 & $<0.001$ \\
\hline C. diandra & 87.593 & $<0.001$ & 69.501 & $<0.001$ & 0.425 & 0.521 & 124.277 & $<0.001$ & 110.765 & $<0.001$ & 37.428 & $<0.001$ \\
\hline C. echinata & 3.551 & 0.069 & 100.018 & $<0.001$ & 109.519 & $<0.001$ & 1.880 & 0.180 & 0.228 & 0.636 & 0.688 & 0.413 \\
\hline C. lepidocarpa & 74.327 & $<0.001$ & 77.804 & $<0.001$ & 4.145 & 0.046 & 90.817 & $<0.001$ & 237.900 & $<0.001$ & 110.952 & $<0.001$ \\
\hline C. pulicaris & 17.836 & 0.001 & 0.000 & 0.993 & 17.956 & 0.001 & 77.197 & $<0.001$ & 17.643 & 0.001 & 50.395 & $<0.001$ \\
\hline C. somedanum & 0.394 & 0.553 & 0.000 & 0.993 & 0.382 & 0.559 & 32.133 & 0.001 & 27.845 & 0.002 & 0.628 & 0.458 \\
\hline E. latifolium & 201.290 & $<0.001$ & 165.610 & $<0.001$ & 61.305 & $<0.001$ & 0.790 & 0.379 & 415.118 & $<0.001$ & 405.110 & $<0.001$ \\
\hline J. alpino-articulatus & 7.075 & 0.190 & 13.689 & 0.002 & 2.068 & 0.172 & 65.576 & $<0.001$ & 44.480 & $<0.001$ & 14.451 & 0.002 \\
\hline P. palustris & 43.093 & $<0.001$ & 33.014 & $<0.001$ & 8.414 & 0.012 & 0.391 & 0.542 & 15.919 & 0.001 & 11.176 & 0.004 \\
\hline P. mixta & 0.170 & 0.686 & 0.196 & 0.665 & 0.001 & 0.978 & 2.397 & 0.144 & 36.889 & $<0.001$ & 27.169 & $<0.001$ \\
\hline P. grandiflora & 4.533 & 0.051 & 0.284 & 0.602 & 2.927 & 0.109 & 119.752 & $<0.001$ & 101.208 & $<0.001$ & 4.209 & 0.059 \\
\hline P. farinosa & 83.077 & $<0.001$ & 83.374 & $<0.001$ & 0.054 & 0.820 & 5.274 & 0.038 & 11.536 & 0.004 & 3.920 & 0.068 \\
\hline S. perennis & 50.763 & $<0.001$ & 50.952 & $<0.001$ & 0.001 & 0.977 & 28.140 & $<0.001$ & 263.498 & $<0.001$ & 167.064 & $<0.001$ \\
\hline T. palustris & 16.322 & 0.001 & 34.256 & $<0.001$ & 7.972 & 0.014 & 0.119 & 0.736 & 0.101 & 0.755 & 0.001 & 0.979 \\
\hline
\end{tabular}


Table 4 Summary of the germination traits of the study species. The species are classified according to the results of the PCA. The time of dispersal was calculated averaging all the collection dates. The predicted period when at least $50 \%$ germination would occur in the field was estimated from the germination results assuming that $22 / 12^{\circ} \mathrm{C}$ (fresh seeds) represented the weather at dispersal in summer, $14 / 4^{\circ} \mathrm{C}$ (fresh seeds) dispersal in autumn, $14 / 4^{\circ} \mathrm{C}$ (cold-stratified seeds) next spring, $22 / 12^{\circ} \mathrm{C}$ (cold-stratified seeds) next summer

\begin{tabular}{|c|c|c|c|c|c|}
\hline Species & Dispersal & $\begin{array}{r}\text { Dormancy at } \\
\text { dispersal }\end{array}$ & $\begin{array}{r}\text { Cold } \\
\text { requirement }\end{array}$ & $\begin{array}{r}>50 \% \\
\text { Germination }\end{array}$ & Optimal $\mathrm{T}\left({ }^{\circ} \mathrm{C}\right)$ \\
\hline \multicolumn{6}{|l|}{ Group A } \\
\hline C. echinata & Jul. & Conditional & Facultative & Dispersal & $30 / 20-22 / 12$ \\
\hline P. farinosa & Jul. & Conditional & Obligatory & Next spring & $30 / 20$ \\
\hline T. palustris & Sep. & Conditional & None & Dispersal & $30 / 20$ \\
\hline \multicolumn{6}{|l|}{ Group B } \\
\hline B. compressus & Aug. & Conditional & Obligatory & $2^{\text {nd }}$ Year & $30 / 20$ \\
\hline C. davalliana & Jul. & Conditional & Facultative & Next summer & $30 / 20$ \\
\hline C. diandra & Aug. & Conditional & Facultative & $2^{\text {nd }}$ Year & $30 / 20$ \\
\hline C. lepidocarpa & Jul. & Conditional & Facultative & $2^{\text {nd }}$ Year & $30 / 20$ \\
\hline E. latifolium & Jul. & Conditional & Facultative & Next summer & $30 / 20$ \\
\hline P. palustris & Sep. & Conditional & Facultative & Next spring & $30 / 20$ \\
\hline S. perennis & Sep. & Conditional & Facultative & Next summer & $30 / 20$ \\
\hline \multicolumn{6}{|l|}{ Group C } \\
\hline C. pulicaris & Sep. & Conditional & Warm req. & Next summer & $22 / 12$ \\
\hline C. somedanum & Sep. & Total & None & $2^{\text {nd }}$ Year & $14 / 4-22 / 12$ \\
\hline J. alpino-articulatus & Sep. & Conditional & Warm req. & Next summer & $22 / 12$ \\
\hline P. mixta & Aug. & Total & Obligatory & Next spring & $14 / 4$ \\
\hline P. grandiflora & Jul. & Total & Facultative & Next spring & $14 / 4-22 / 12$ \\
\hline
\end{tabular}




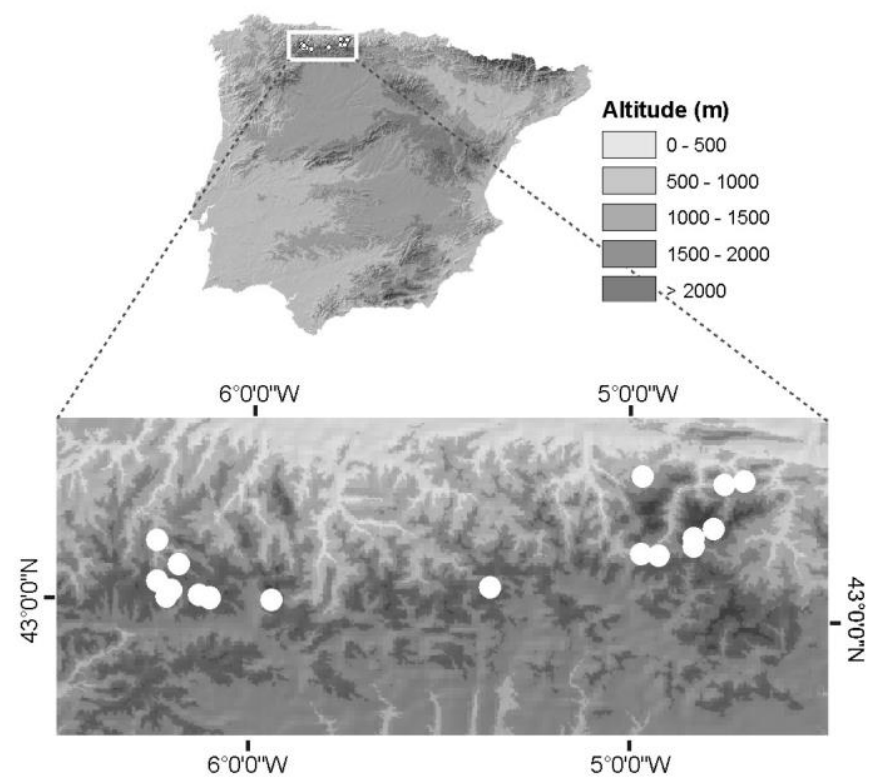

Fig. 1 Location of the study area in the Cantabrian Mountains of northern Spain. The white circles indicate the eighteen fen sites selected for seed sampling 

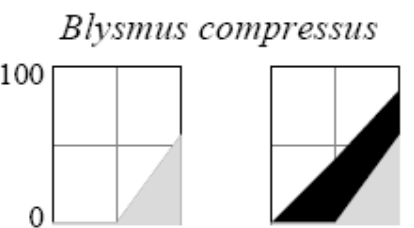

Carex echinata
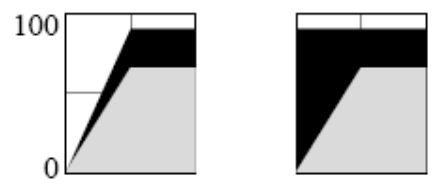

Centaurium somedanum
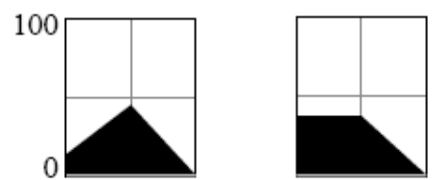

Parnassia palustris
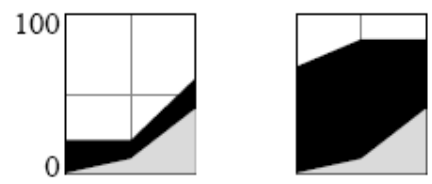

Primula farinosa

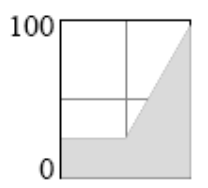

$14 / 422 / 1230 / 20$

WARM

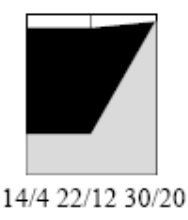

COLD
Carex davalliana
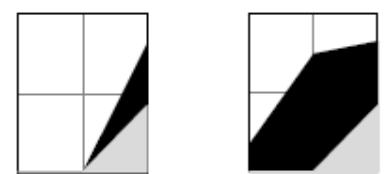

Carex lepidocarpa
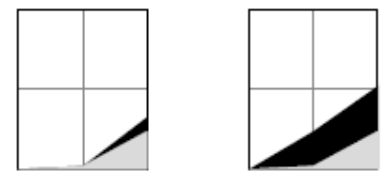

Eriophorum latifolium
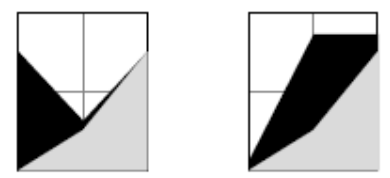

Pedicularis mixta
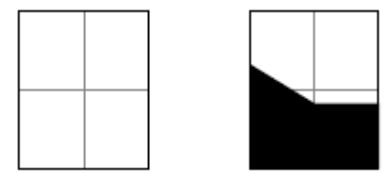

Swertia perennis

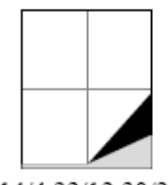

$14 / 422 / 1230 / 20$

WARM

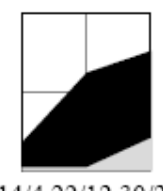

$14 / 422 / 1230 / 20$
COLD
Carex diandra
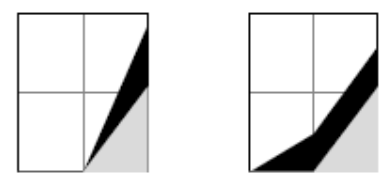

Carex pulicaris
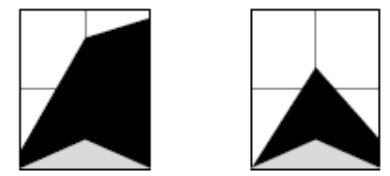

Juncus alpino-articulatus
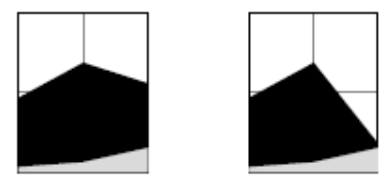

Pinguicula grandiflora
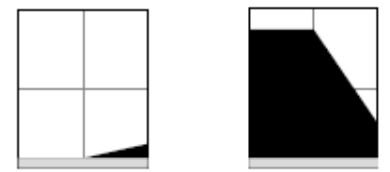

Triglochin palustris
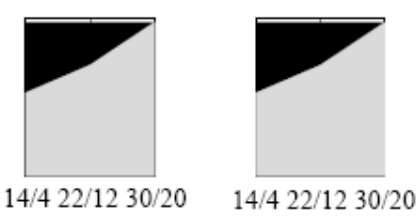

WARM

COLD

Fig. 2 Effect of stratification on seed germination and dormancy loss across the range of germination thermoperiods $\left(14 / 4{ }^{\circ} \mathrm{C}, 22 / 12^{\circ} \mathrm{C}, 30 / 20^{\circ} \mathrm{C}\right.$ ). The grey areas represent the germination percentages (from 0 to $100 \%$ ) of fresh seeds, the black areas the significant increases (GLMM, p < 0.05 ) of germination percentages at each thermoperiod produced by warm (left blocks) and cold (right blocks) stratification. The germination percentages were calculated averaging treatments that were not significantly different $(p>0.05)$ 


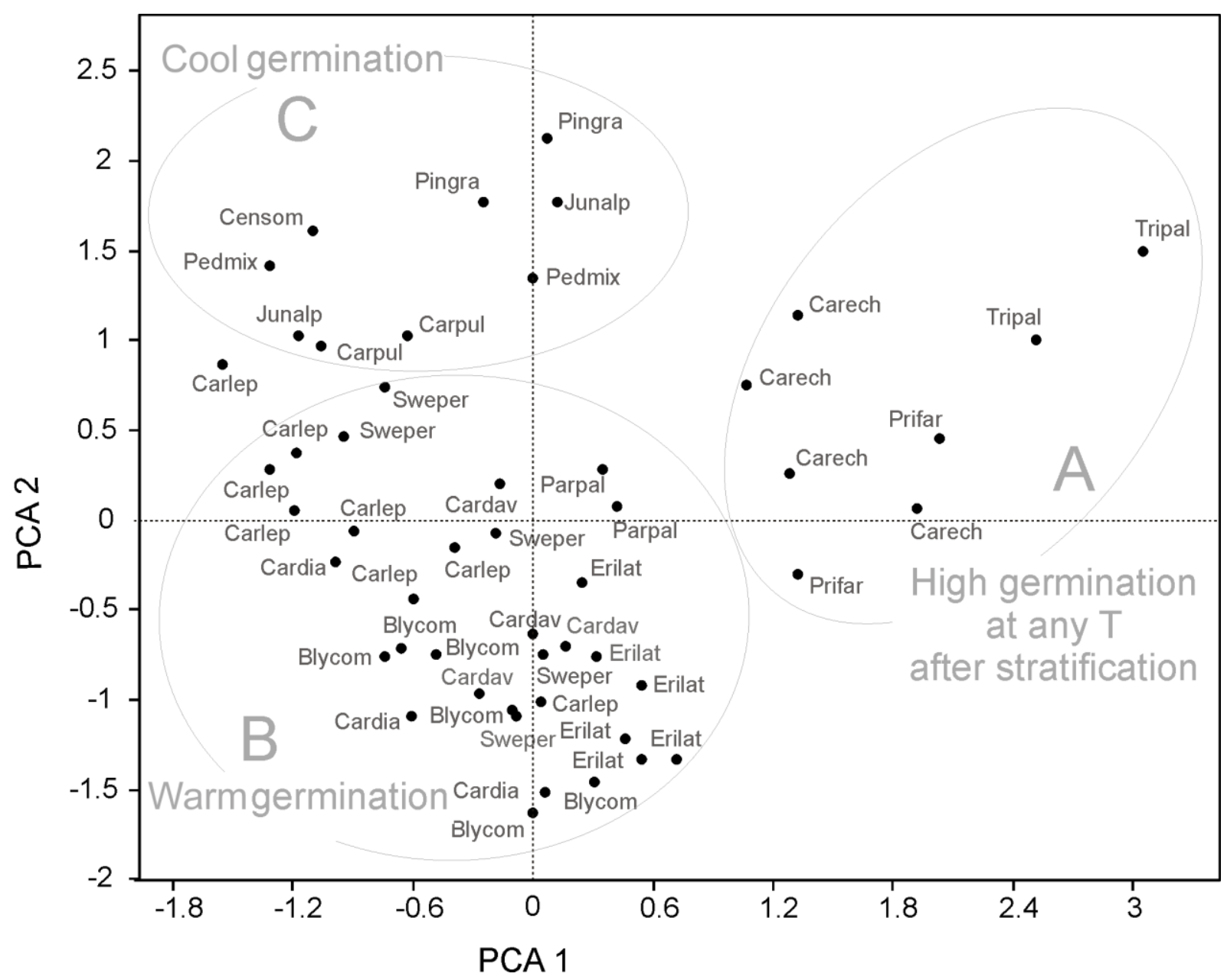

Fig. 3 Principal Component Analysis (PCA) representing the main two axis of variation on the germination patterns. Only the results of fresh and cold stratified seeds were analyzed. Each spot represents a collection and its species is indicated by the three first letters in the genus name and the specific epithet. The collections are clustered in three main groups according to their correlation with the variables and the germination behaviour of the species 